\title{
Resonance Stirling Engine producing heat and power (CHP)
}

\author{
R. Schmid ${ }^{1},{ }^{1}$ Rud. Schmid AG, CH-3174 Thörishaus, Switzerland \\ J.P. Budliger ${ }^{2},{ }^{2}$ Consultant, $\mathrm{CH}-1228$ Plan-les-Ouates, Switzerland \\ info@stirling.ch; jean-pierre.budliger@infomaniak.ch
}

Keywords: Stirling, Free Piston, Resonance, Stability, Performance, Applications

\begin{abstract}
The free-piston Resonance Stirling engine forms a new "electricity producing heating system". Its compact assembly operates reliably and at high efficiency, setting new standards for small heating systems. Complete units are currently submitted to a prolonged test program, preparing their production at an industrial scale.

The engines are heated from outside by a FLOX-burner (flameless flue gas recirculation burner), exposing the working gas to high temperatures. Even at low excess air rates the flue gases are virtually free of pollutants.

The free pistons of this resonance concept oscillate in a perfectly stable mode, entailing an important cyclic pressure swing to the working gas. The electric efficiency exceeds $25 \%$ and total efficiency (electricity + useful heat) lies above 90\%. The heating power of the fuel is used with high benefit, promising a widespread application to this new technology.
\end{abstract}

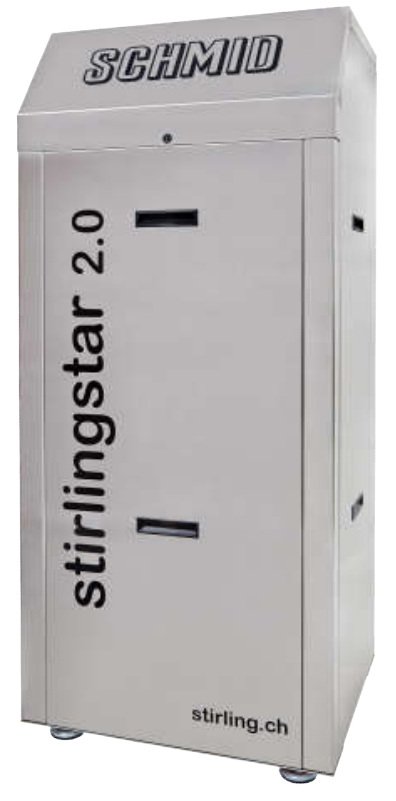

\section{Use of small heat and power units}

Nuclear power production will continuously be replaced by renewable energies, in particular solar energy. However, during the cold season when most heat is needed, renewable energies will only partly cover the requested services. Combined Heat and Power Units (CHP) may then suitably step in to bridge any power gap.

The new resonance free-piston Stirling concept constitutes an ideal solution to provide smaller homes with heat and electricity, in complying with stringent standards existing for residential areas.

\section{The free-piston resonance Stirling concept}

The internationally patented resonance Stirling engine comprises a displacer, which is rigidly fixed to the power piston (see fig. 1). The amplitude and phase of this oscillating transfer piston are accurately controlled by the associated electric linear generator. In addition, the working volume comprises well tuned resonance pistons, oscillating freely in a stable regime, imparting a periodic pressure change to the working gas. They act as an impedance of the gas circuit, increasing the pressure variation and shifting it against the movement of the transfer piston for achieving an optimized work output.

The whole assembly is placed within a hermetically sealed casing. The free pistons are centered by gas bearings, avoiding any contact with the cylinder. By the absence of any gearing system no lubrication is needed, making it possible to operate these engines for long, virtually maintenance-free service periods. 

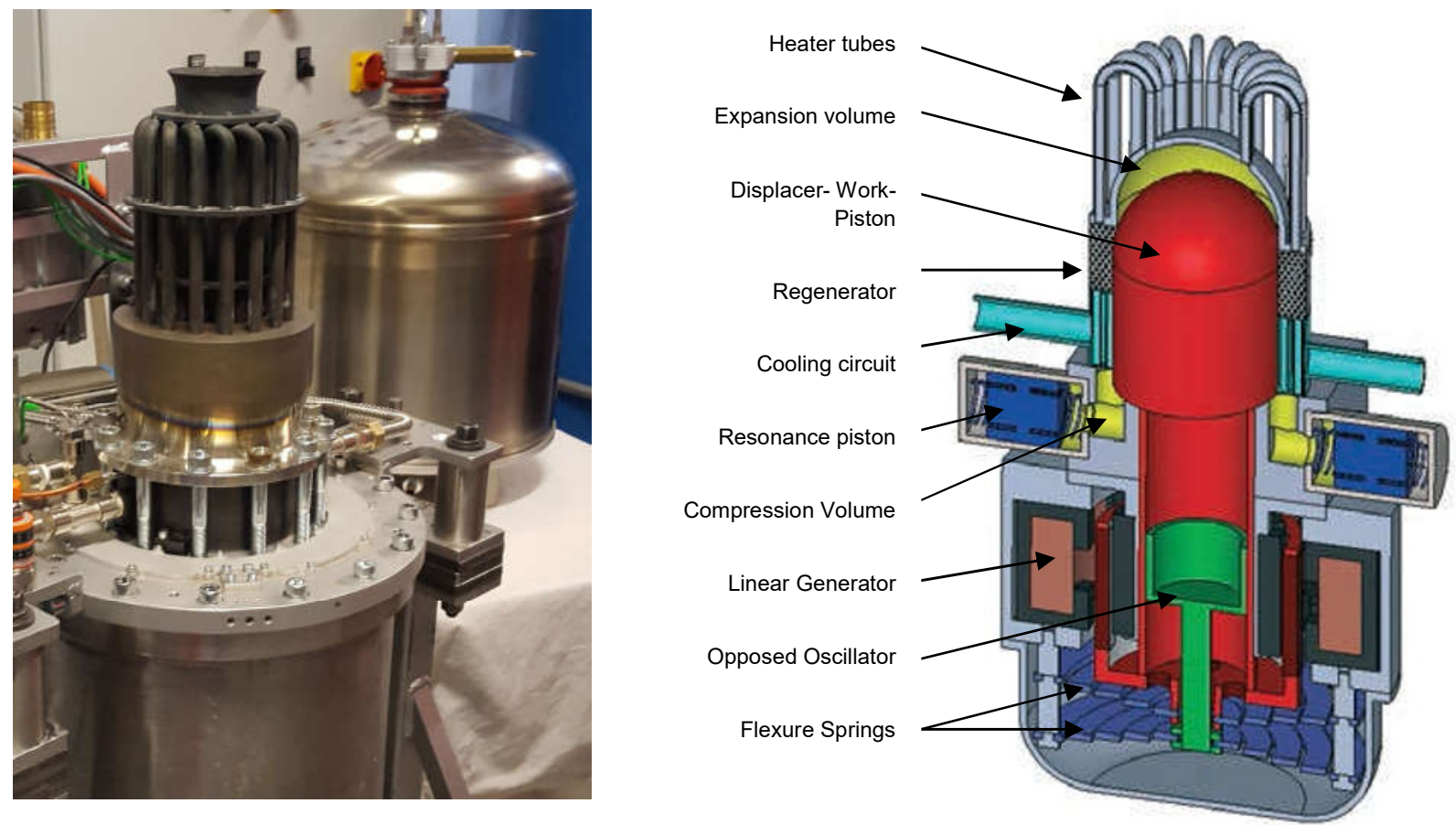

Figure 1: Prototype unit with removed burner envelope
and schematic cross-section of the mechanical assembly

(the movement of the pistons may be seen under: www.stirling.ch\Animation

\subsection{Operation of engine prototypes}

Several prototypes have been built and submitted to prolonged tests. The measured experimental results are compared with analytical data, making it possible to continuously assess and implement further improvements to the process.

\begin{tabular}{|c|c|c|c|}
\hline Test Results (March 2019) & & At full power & At part-load \\
\hline Max. Combustion heat input & $\mathrm{W}_{\mathrm{TH}}$ & 8'000 & $5^{\prime} 000$ \\
\hline Electric power output & $\mathbf{W}_{\mathbf{E L}}$ & 2'000 & $1^{\prime} 200$ \\
\hline Available heating power & $\mathbf{W}_{\mathrm{TH}}$ & $5 ’ 300$ & $3 \cdot 300$ \\
\hline Electric efficiency $\eta_{E L}$ & $\%$ & $>25$ & $>23$ \\
\hline Total efficiency ท́тот & $\%$ & $(90)$ & $(90)$ \\
\hline Modulation range & $60-100 \%$ & $100 \%$ & $60 \%$ \\
\hline Pressure ratio $\left(\pi_{\mathrm{C}}\right)$ & $\mathrm{p}_{\mathrm{MAX}} / \mathrm{p}_{\mathrm{MIN}}$ & $1.35-1.40$ & $1.30-1.35$ \\
\hline Operating frequency f & $\mathrm{Hz}$ & \multicolumn{2}{|c|}{50} \\
\hline Dimensions $\mathrm{W} / \mathrm{D} / \mathrm{H}$ & $\mathrm{cm}$ & \multicolumn{2}{|c|}{$60 / 70 / 120$} \\
\hline Mass & $\mathrm{kg}$ & \multicolumn{2}{|c|}{ ca. 180} \\
\hline Energy source & & \multicolumn{2}{|c|}{ Biogas / Natural gas / LPG } \\
\hline
\end{tabular}

The major operating characteristics of the last prototype unit are summarized in the table above. Electric efficiencies of more than $25 \%$ have been measured when heater tube temperatures were kept at around $800^{\circ} \mathrm{C}$. 


\subsection{Engine characteristics}

In Figure 2, typical operating characteristics of the presently known Stirling engine and of the new resonance concept are compared with each other. The broken lines show the expected thermodynamic performance for these two engine concepts, under assumed mechanically stable conditions. This plot readily shows that the two engine configurations would reach similar performance levels when operated at an assumed nominal gas temperature at the heater head of some $700^{\circ} \mathrm{C}$.
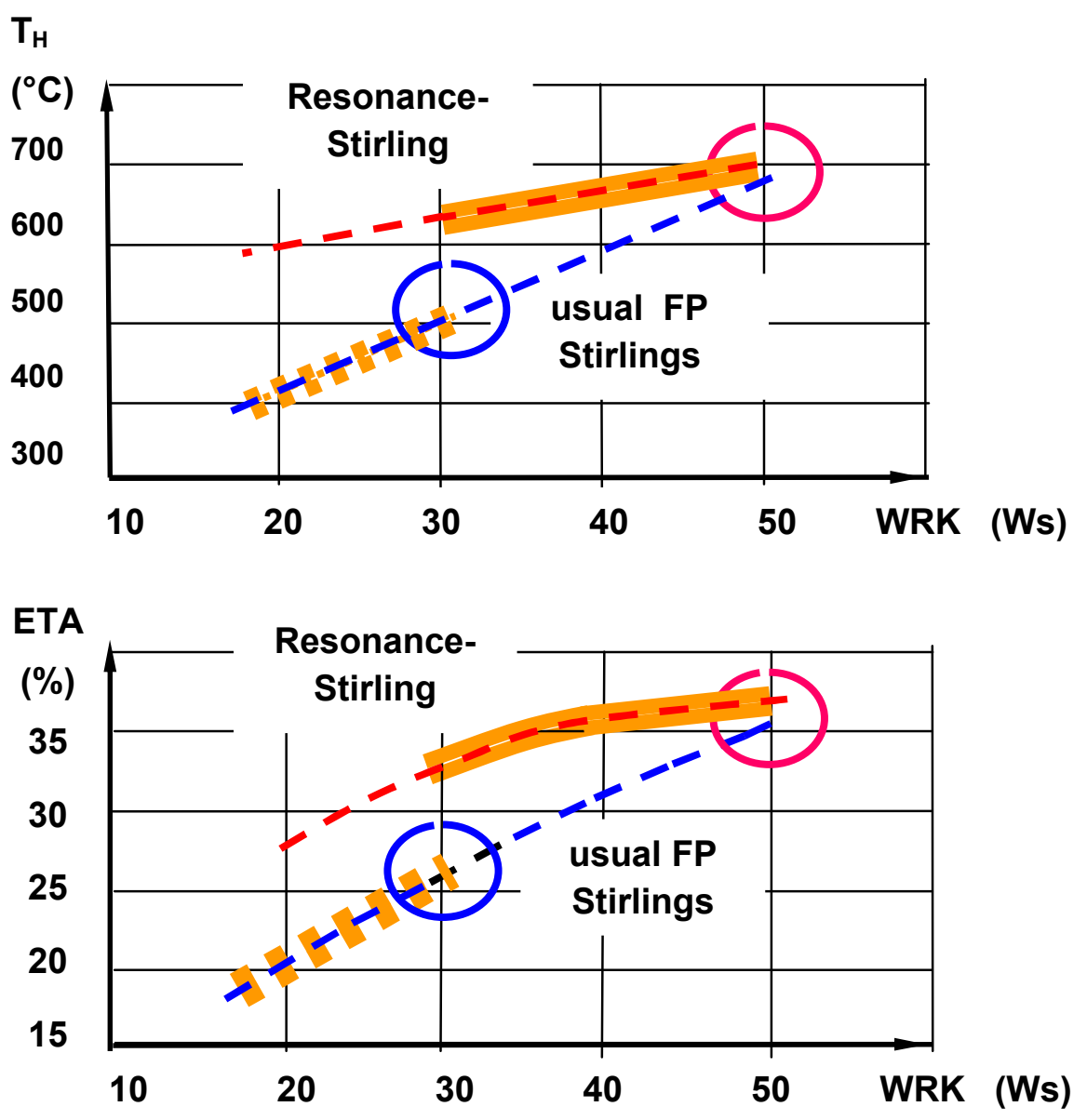

\section{Fig. 2: Heater tube temperature $T_{H}$ and thermal cycle efficiency ETA as a function of the cyclic work WRK of the engines}

The resonance Stirling engine operates in a perfectly stable mode at high heating temperatures and correspondingly important pressure ratios $\pi_{\mathrm{C}}$, resulting in the above-indicated performance rates. The high efficiency results from the high temperature, under which the gas is expanded. In addition, owing to the important pressure ratio, the gas flow rate through the regenerator and associated losses are relatively moderate.

The new engine is characterised by favourable part-load operating conditions. By adjusting the heat delivery of the burner, the engine power output may be set according to the heating demand of the dwelling. The engines may thus be operated smoothly and efficiently, without exposing them to an important thermal fatigue. By equipping these installations with an appropriate hot water boiler, on-off cycling can be reduced to a minimum.

All other, presently existing free piston engines can be operated in a stable mode only up to a rather moderate heater temperature, what limits their efficiency and power density (see bold 
characteristic curves). At given piston dimensions, maximum electric power output remains below $1.2 \mathrm{~kW}_{\mathrm{EL}}$, what limits also their economic value.

The new conceived engines are laid out for an operation at $50 \mathrm{~Hz}$. The electricity produced can directly be fed into the local power grid, without the use of any inverter, thus free of any conversion losses. Also, the control system required to operate an engine at a fixed frequency is rather simple.

\subsection{Engine burner}

The combustion air is first preheated to high temperatures in a counter-current heat exchanger by means of the exhausting gas stream. In the burner, this preheated air is diluted with recirculating exhaust gas, before being mixed with the combustible gas. Combustion then takes place in a flame-free oxidation (FLOX-) process. Even with low excess air rates, complete combustion is achieved without producing any noticeable amount of noxious effluents $(\mathrm{CO}$, $\mathrm{NO}_{\mathrm{X}}$ ). An additional condensing heat exchanger serves to extract humidity contained in the exhaust gas stream and to efficiently use its residual heat content.

\subsection{Vibration suppression}

The resonance pistons are arranged in pairs, oriented orthogonally to the main piston; by their opposed movement, no net force is exerted upon the engine.

The displacer-power piston is associated with an additional oscillating mass, forming together a dual pendulum. By their opposed movement, the vibration of the engine body is reduced to a minimum.

\section{Current field test program}

Very recently, 5 field test engines have been built, each with an electric output of $2 \mathrm{~kW}_{\mathrm{EL}}$. These engines are currently installed at the site of the first clients, who will operate them at least during 2 years, according to an established program. All test runs will be recorded and analysed, monitoring the fuel savings which may be realised under diverse operating conditions. More detailed information on specific applications will be dealt with in the course of the conference.

These prototype units are laid out as a standardised, commercial product, set up in collaboration with a heating equipment company, according to the rules and quality requirements imposed to these products. Sales and customer services may then be carried out in a joint undertaking.

\section{Complementary role of CHP-units to renewables}

The complementary functions of renewable energy devices and of CHP-units may best be illustrated by the scheme of Fig. 3. Most of the energy is supplied without any significant greenhouse gas emissions. The combination of a PV-array and a CHP-unit may benefit of a common set of batteries and a current inverter.

In addition, this assembly may be used to recharge electric vehicles very conveniently at home, during time periods when a surplus of electricity is available. The electric vehicle only consumes the charged power, the waste heat of the CHP remaining available for heating purposes. Instead of consuming about $61 / 100 \mathrm{~km}$ with a petrol engine (releasing substantial amounts of waste heat into the atmosphere), the electric vehicle consumes an equivalent energy of only about $21 / 100 \mathrm{~km}$. 
The CHP-unit is operated by means of natural gas or LPG, releasing greenhouse gas into the atmosphere. This negative climatic effect is however largely compensated by the benefits resulting from energy-efficient electric vehicles, which most of the time will be fed with renewable energies.

It may also be noted that natural gas will in future be blended with a high fraction of renewable gases (biogas or hydrogen from power-to-gas plants). The emission of greenhouse gas will be reduced accordingly. In addition, the use of biomass for operating the Stirling engine entirely with renewable resources is investigated.

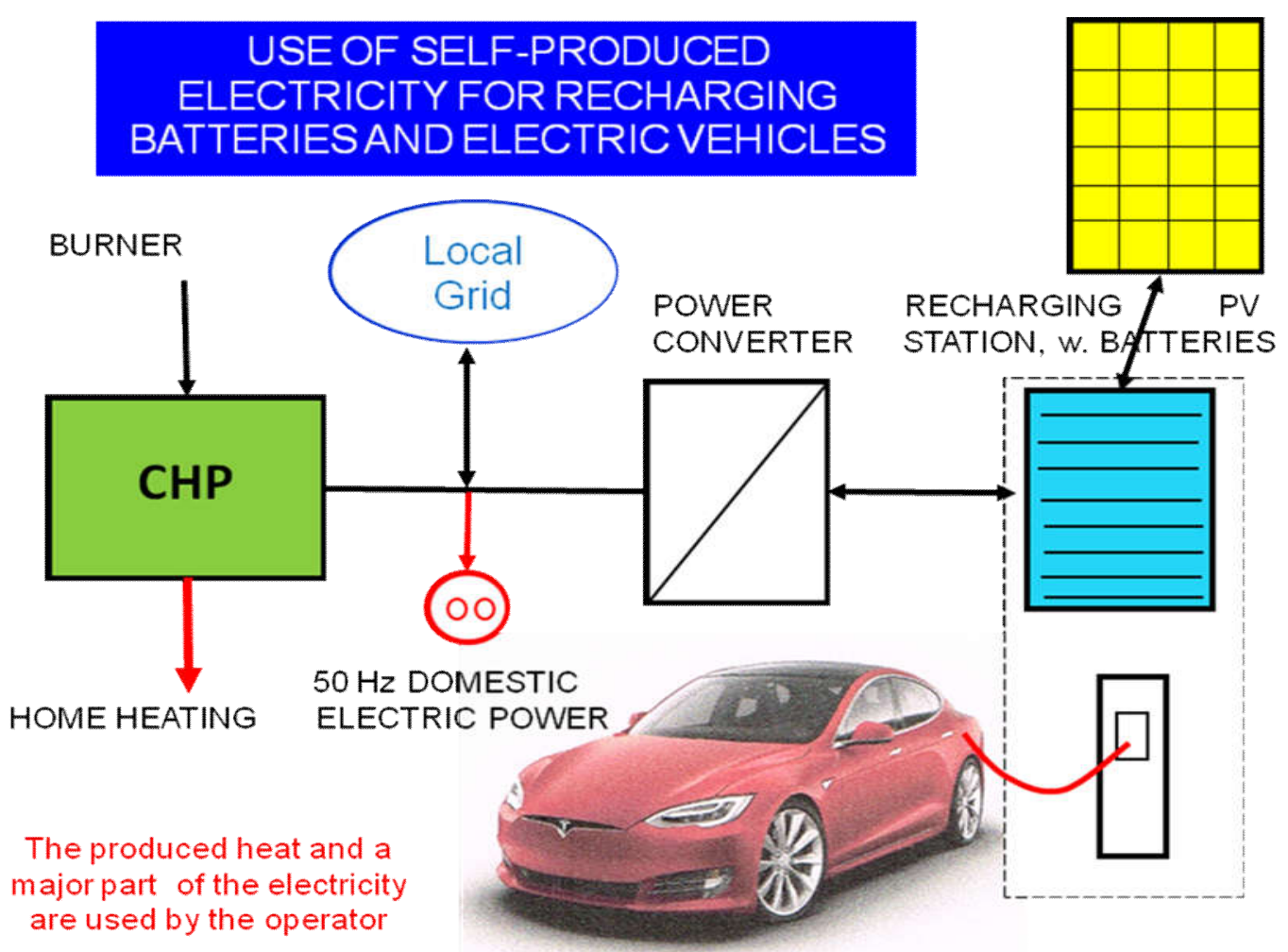

\section{Figure 3: CHP-Assembly for domestic use, including batteries, a PV-collector and a charging facility for electric cars}

\section{CHP in a renewable energy supply scheme}

The fossil fuel consumption, resulting in a continued heating of our atmosphere needs to be replaced as rapidly as possible by renewable resources (solar, wind, hydraulic energy). The question then arises whether CHP-units operating with fossil fuels remain acceptable. This dilemma may explain the rather limited support devoted to this technology.

In recent years, substantial progress has been made in the development of these renewable resources. By series production, their cost has been lowered, making them economically competitive. Nevertheless, the energy supplied from these renewable resources strongly depends upon weather and seasonal conditions. Any lacking supply must be covered by stored reserves, rapidly and in large quantities. 
Electric batteries, as well as hydraulic storage in the mountains are the predominant resources for covering temporary shortages, e.g. for equilibrating day- and night demand. These storage means have limited capacities and may not be used for covering longer lasting deficiencies. The investment cost of these facilities would otherwise have to be paid back with a reduced number of storage cycles; the specific cost per $\mathrm{kWh}$ becomes high, reducing considerably their attractiveness.

The high power density of fossil fuels is an important asset, making them highly suitable for storing large amounts of energy over long time periods. They can be transported at low cost for producing electricity, almost anywhere. By their simple use, mankind consumes this resource in an abusive way, in a large variety of applications. The released greenhouse gas leads to a continuous heating of the atmosphere, obliging us to drastically reduce our dependence on fossil fuel.

Despite of the intensive research carried out to develop alternative energy storage means being free of a climatic heating effect, no alternative techniques to the hydrocarbon cycle was identified. Nature is based on the most powerful storage concept. Fossil fuel should exclusively be used as a longer-term energy storage means, for covering longer lasting deficiencies of renewable energies.

CHP then represents an ideal concept for converting the released combustion heat efficiently into electricity. As power deficiencies occur mainly during the cold season, the heat released from this process may usefully serve for heating purposes. Furthermore, fossil fuels may also be blended with renewable gas, as e.g. with hydrogen gained by electrolysis, operated with any surplus of renewable electric resources.

The recently improved, series-produced solar PV-panels and wind turbines play a central role for achieving this ambitious transition. Considerable investments are needed within short time, in order to prevent a dramatic climate change. Fossil fuel consumption should be reduced as rapidly as possible, e.g. by 5 to $8 \%$ annually against the previous year.

Young people demonstrate and ask for rapid action to preserve the climate. They recognize the threatening evolution taking place and that they will inherit the weather and living conditions left over by our elder generation. It remains to be hoped that young people will also comply with the general demand for an appropriate individual attitude, by lowering their own daily fuel consumption, based on slow mobility, limited travel demand or reduced comfort conditions.

In summary, a rapid conversion to renewable energy resources is mandatory. Fossil fuel will still be needed to cover supply gaps and to ensure energy security. CHP will be used to efficiently convert the released combustion heat into electricity.

\section{Conclusions}

The Resonance Stirling Engine is a new CHP-concept operating with free pistons. This engine comprises a combined displacer-work-piston, whose periodic movement may accurately be controlled by its associated linear electric generator. Each unit comprises elastically suspended resonance pistons, which by their oscillating movement induce a periodically changing working gas pressure. By exposing the heater head to high temperatures, mechanical energy is produced and extracted by the engine linear generator in form of electric energy.

Their safe and reliable operation has been confirmed by test engines, operating in a stable mode. By operating them at high heating temperatures, electricity and heat are generated efficiently and economically. Engine operation is highly flexible and may be adjusted 
according to demand, ensuring a reliable power supply. The flue gases of the flameless combustion process (FLOX) are clean and comply with stringent regulations imposed for their operation in residential areas.

The non-lubricated mechanical assembly is hermetically confined, thus reducing the service demand of the entire unit to a periodic inspection of the burner. The units are compact and well suited for replacing e.g. old and used gas heating systems. Noise and vibration are minimal.

A field test program has been initiated to demonstrate the reliable and efficient operation under various service conditions. Cooperation with specialists of the heating power industry ensures that these units comply with the numerous specifications imposed. A joint program is currently prepared for launching publicity and sales of this new product.

To limit the threat of global warming, renewable energies will have to replace to maximum possible extent the current, abusive consumption of fossil fuel. Short-term interruptions in solar energy supply can be bridged by batteries and by other stored energy sources. Fossil fuels should exclusively be used to cover longer renewable power deficiencies. These fuels contain chemical energy at high density, making them ideal for storing energy. Despite of intensive research on a variety of options, they are difficult to be replaced and will remain mandatory for securing a reliable supply of electricity.

As long as fossil fuel will be used for covering these energy supply gaps, CHP serves ideally for converting the combustion heat into electricity. Deficiencies in renewable energy supply occurring mostly during the cold season, the heat released from CHP-operation may be used for heating purposes. Furthermore, for lowering the release of greenhouse gas, fossil fuel may be blended with renewable gas, as e.g. with hydrogen gained by electrolysis, operated by any surplus in renewable electric energy. In addition, the use of renewable biomass in Stirling engine burners is actively investigated.

\section{References:}

[ 1 ] : US 2013/0031899 A1: STIRLING MACHINE (Feb. 7, 2013)

[ 2 ] : ISEC-17: The Resonance Stirling System (2016)

[ 3 ] : ISEC-18: The Resonance Stirling System (2018)

[4]: www.stirling.ch 